\title{
Collégiales et chapitres cathédraux au crible de l'opinion et de la Révolution
}

\section{Philippe Bourdin}

\section{(2) OpenEdition \\ 1 Journals}

Édition électronique

URL : https://journals.openedition.org/ahrf/804

DOI : 10.4000/ahrf.804

ISSN : 1952-403X

\section{Éditeur :}

Armand Colin, Société des études robespierristes

\section{Édition imprimée}

Date de publication : 1 mars 2003

Pagination : 29-54

ISSN : 0003-4436

\section{Référence électronique}

Philippe Bourdin, «Collégiales et chapitres cathédraux au crible de l'opinion et de la Révolution »,

Annales historiques de la Révolution française [En ligne], 331 | janvier-mars 2003, mis en ligne le 18 avril 2008, consulté le 22 avril 2022. URL : http://journals.openedition.org/ahrf/804 ; DOI : https://doi.org/ 10.4000/ahrf.804 


\title{
COLLEGIALES ET CHAPITRES CATHEDRAUX AU CRIBLE DE L'OPINION ET DE LA RÉVOLUTION
}

\author{
PHILIPPE BOURDIN
}

\begin{abstract}
La suppression des chapitres par la Constitution civile du clergé reposa pour une large part sur l'image noire qui leur était accolée. Elle résultait pour une part des polémiques antireligieuses du siècle qui condamnaient sans nuances les mondes clos, au titre desquels moines et chanoines étaient confondus, et qui trouvaient leur traduction dans le théâtre ou le roman pornographique, à un degré bien moindre dans la caricature. Elle était aussi fondée, à bien lire les cahiers de doléances, sur une condamnation du régime seigneurial et de la pression fiscale auxquels contribuaient nombre de propriétés capitulaires, sur la revendication d'une ouverture du recrutement des compagnies, sur la nécessité d'une utilité sociale que viendrait prouver une œuvre pastorale, éducative et philanthropique. Les chanoines députés à l'Assemblée nationale constituante, peu prolixes ou sous la domination des évêques, ne surent convaincre leurs pairs d'une rédemption possible et, malgré des protestations organisées au niveau provincial, assistèrent impuissants au vote de leur arrêt de mort.
\end{abstract}

Mots clés : anticléricalisme ; chanoines ; histoire religieuse de la Révolution ; Constitution civile du clergé ; cahiers de doléances.

Le 21 avril 1790, le rapport Martineau, qui deviendra la matrice de la Constitution civile du clergé, est déposé sur le bureau de l'Assemblée nationale. Il affirme fortement : « Nul ne doit vivre de l'autel, que celui qui sert l'autel; nul ne doit subsister aux dépens du public, que celui qui sert le public. [...] Il n'y a et ne peut y avoir dans l'église d'emplois légitimes que ceux qui ont des fonctions extérieures, la charge d'instruire les peuples, de leur administrer tous les secours spirituels. Tout autre emploi est un emploi parasite, un abus dans l'ordre de la nature et de la religion. Il faut se hâter de l'extirper»(1). La suppression des bénéfices, qui servent à «consumer

(1) Jean MADIVAL, Emile LAURENT, Archives parlementaires de 1787 à 1860, $1^{\mathrm{re}}$ série [on notera désormais simplement AP], tome XIII (14-21 avril 1790), Paris, 1882, p. 168.

Annales historiques de la Révolution française - 2003 - AP 1 [29 à 54] 
dans l'oisiveté une partie des revenus publics », est réclamée. C'est la mort annoncée des chapitres que çà et là des cahiers de doléances proposaient de réformer en profondeur. Leurs prélèvements économiques, l'absentéisme et les abus d'une minorité de leurs membres, leurs querelles intestines, les discours littéraires autour du personnage du chanoine, n'avaient pas peu contribué, il est vrai, à ternir leur image sociale aux yeux d'une minorité éclairée, à les ranger parmi les vestiges surannés d'un ancien temps qui, la Révolution venue, va devenir l'Ancien Régime. Faut-il y voir l'une des conséquences « de cette jalousie bourgeoise [constatée par Sieyès] qui tourmente l'habitant des petites villes contre Monsieur le chanoine » (2) ? Ou la traduction du constat fait par le curé Meslier : «Les oiseaux sauvages chantent et ramassent assez dans les champs et les bois; les peuples n'ont que faire de nourrir si grassement tant de gens pour ne faire que chanter dans les temples »(3)? Richesse, parasitisme, ambition effrénée, égoïsme et avarice, qui nourrissent les actes d'accusation, ne peuvent pas passer pour des thèmes bien neufs en 1789 ; les chapitres de Guyenne par exemple en ont fait les frais depuis le $\mathrm{XVI}^{\mathrm{e}}$ siècle (4). Mais leurs conséquences législatives, deux cents ans plus tard, interrogent d'autant plus sur la forme et les effets de l'image ainsi construite et réutilisée contre ce que Philippe Loupès distingue comme un moyen clergé - laissant au plus haut les dignitaires des cathédrales et les membres des chapitres nobles -, fort de 12000 à 15000 membres regroupés en près de sept cents compagnies qui frappent par leur diversité et sont inégalement réparties sur le territoire (très présentes dans les pays de Loire, $60 \%$ cependant sont établies au sud d'une ligne Borde aux-Valence, plus de $53 \%$ privilégiant les villes d'au moins deux mille habitants).

\section{La perversion de l'image sociale des chapitres}

Les chapitres séculiers ne présentent sans doute pas aux yeux des Français du XVIII ${ }^{\mathrm{e}}$ siècle le mystère des mondes clos dans lesquels une minorité d'individus s'enferment par des vœux perpétuels, quoique la confusion parfois existante entre chanoines et moines joue en défaveur des premiers, associés dans l'opprobre qui condamne la vie régulière - et que mènent de facto les chapitres dits «nobles » d'hommes ou de femmes. Une compagnie de chanoines a pour finalité première sa fonction orante, au nom de laquelle

(2) Cité par Michel VOVELLE, «Un des plus grands chapitres de France à la fin de l'Ancien Régime : le chapitre cathédral de Chartres », Actes du quatre-vingt-cinquième congrès national des sociétés savantes (Chambéry-Annecy, 1960), Paris, 1961, p. 235. p. 282.

(3) Cité par Maurice DOMMANGET, Le curé Meslier, athée, communiste et révolutionnaire, Paris, 1965,

(4) Philippe LOUPES, Chapitres et chanoines de Guyenne aux XVII et XVIII' siècles, Paris, 1985, p. 395. 
elle assure une présence physique quotidienne dans des cérémonies religieuses, des rites, des processions qu'elle enrichit de chants en psalmodie, plain-chant ou faux-bourdon; elle conseille l'évêque, veille les tombeaux des seigneurs fondateurs par des prières perpétuelles, conserve fréquemment de précieuses reliques. Fier de son antiquité, de sa grandeur, de sa réputation, termes qui abondent dans les registres capitulaires et autour desquels se sont construits un conservatisme et un attachement aux privilèges, aux préséances, certains, le chapitre joue un rôle social, intégrant nombre de cadets de la noblesse et des bourgeoisies urbaines. Il reproduit aussi en son sein un monde hiérarchisé en fonction du haut- et du bas-chœur et des dignités (doyen, prévôt, prieur, trésorier, sacriste, chantre, archidiacre, etc.), un monde remarquable par les solidarités familiales qui s'y expriment et les carrières qui s'y construisent dans la durée. Le chapitre enfin a une existence économique : il gère fondations et bénéfices, fiefs et seigneuries urbains ou ruraux, la plupart du temps riches en dîmes, champarts, lods et ventes, rentes de toutes sortes; il dépense pour la fabrique, la psallette, diverses charges cultuelles, les bâtiments, mais aussi pour le service de la dette, pour les congrues, pour ses procès. Car, si son vécu juridique, excepté l'exercice de la justice seigneuriale, n'est censé concerner d'abord que l'officialité, les intérêts collectifs que les chanoines défendent contre propriétaires ou locataires, les querelles individuelles qui les opposent fréquemment les uns aux autres, jusqu'au sein du chœur, les projettent sur la place publique et les poussent à une fréquentation assidue des notaires et des hommes de loi.

Dans les années 1770 et au début des années 1780, le chapitre SaintPierre de Clermont-Ferrand est ainsi divisé en deux clans irréconciliables, déchirés par un débat sur une règle commune aux collégiales de son diocèse, règle jusqu'alors absente en plus d'une, que cherche à imposer l'évêque Bonal. Les conservateurs de Saint-Pierre, qui dans l'ordre épiscopal voient surtout le risque de perdre un pouvoir acquis par l'ancienneté, deviennent la risée de l'opinion commune. Les réformateurs, menés notamment par Pascal-Antoine Grimaud et Jean-Baptiste Monestier, font circuler contre leurs adversaires au moins cinq pamphlets manuscrits et anonymes (un anonymat vite levé par les principaux outragés) : entre autres, La ménagerie des animaux, Le combat des animaux, Le Ballet (5). Seule nous est restée la première de ces œuvres, l'Épître adressée à M. Dumas, doyen du chapitre Saint-Pierre. Elle développe, après des considérations sur la justice séculière, une série de remontrances ironiques et sévères adressées au doyen aveugle, à son comportement, à sa vêture, à sa manière d'observer les rituels. Dumas

(5) Philippe BOURDIN, Le noir et le rouge. Itinéraire social, culturel et politique d'un prêtre patriote (1736-1799), Clermont-Ferrand, Presses Universitaires Blaise-Pascal, 2000, pp. 134 etsqq. 
est rendu à de multiples états animaux et aux perversités inhérentes, telles que les fables pouvaient les camper :

«Parce que vous ne voyés pas vous croyés être invisible. Vous croyés en cachant votre tête comme l'autruche que le reste du corps est caché. Il vous sied bien de raisonner comme cet animal. La tête est ches vous ce qu'il y a de moins remarquable. Elle va par des ressorts qu'il est aisé de deviner [...]. Vous prenés quelquefois la forme du lion mais dans cet accoutrement bizarre vous etes tout au plus un loup garoux qui ne fait peur qu'aux enfants. Vos oreilles dont le bout s'allonge trahisse le mystere. Les pattes de l'animal divertissent au lieu d'effrayer. On luy met un licol et une muselière. Il est promené dans les riies pour servir de spectacle aux passants. Cependant cet animal se redresse a cause de quelque difference apparente mais il ne sait pas que c'est un tapis que l'on met sous ses pieds comme sous ceux du chameau. Ce n'est point par respect c'est pour menager sa foiblesse dans sa chute ainsi que l'honneur dans son corps. » (6)

Cette arche de Noé revisitée, ce fatras de références et d'approximatives métaphores révèlent un plaisir certain pris à la chicane. Attaques ad hominem, réduisant physiquement et intellectuellement un adversaire déshumanisé, se doublent d'une remise en cause morale. Simoniaque, le doyen s'enrichirait de la fortune des moribonds et des avantages retirés des secrets du confessionnal. Il se laisserait aller à une sexualité débridée, tout comme ses complices : l'auditeur aux comptes, sous le charme de l'épouse gourmande de l'organiste à laquelle il a donné deux enfants, « lève souvent ses bras vers le ciel mais cette posture serait pour lui bien moins gênante s'il vuidoit ses mains »; le baile, qui «inonde la sacristie de crachats infects », interdit de séjour dans un couvent voisin où il courait jupon, s'est rabattu sur trois filles du peuple dont une lingère réputée le «repasser entre deux draps »; le chantre partage les faveurs de ces dernières quand il n'estropie pas les matines par ses balbutiements convulsifs. Peignant ce monde impie livré au péché de luxure, ses contempteurs, en calomniant la moitié de leur propre collégiale, reprennent donc à leur compte arguments et images qu'ils offrent aux anticléricaux : «On s'attend bien [concluent-ils à l'adresse des agressés] à entendre croasser cette volée de corbeaux mais dans un siècle éclairé comme le nôtre le croassement ne présage rien de sinistre ».

Avec Carmontelle (1717-1806), le chanoine devient d'ailleurs personnage de théâtre comique. Attaché au duc d'Orléans, dessinateur topographe, aquarelliste et portraitiste médiocre - figeant ses personnages dans des attitudes de marionnettes -, Carmontelle se fait bientôt amuseur des Grands. Il publie abondamment pour l'un des genres théâtraux qui fait le bonheur des salons jusqu'à la Révolution, les proverbes, des piécettes sans véritable intrigue ni dénouement, dont il compose dix volumes de 1768 à 
1781. Productions pleines d'esprit sur les ridicules de son temps, elles sont bientôt récupérées par les théâtres de boulevard. En a-t-il été ainsi pour Le chanoine de Reims, l'abbé de la Craie, comme le nomme humoristiquement l'auteur (7) ? Quatre personnages sont en scène, outre l'ecclésiastique : un homme âgé qui a été spectateur du sacre de Louis XV; un auteur qui vient recueillir son témoignage sur l'événement; un décorateur des MenusPlaisirs et son valet (qui sont surtout cités dans la distribution pour rappeler que l'abbé ne dédaigne pas le superflu); la vieille gouvernante de M. de la Craie. Durant quatre scènes, l'ecclésiastique est attendu par ses hôtes. Il est mieux occupé à vérifier l'état de ses vignes, dont il fait commerce (incidemment, sa gouvernante propose de vendre quelques bouteilles aux visiteurs), et à échanger sur ce thème avec le doyen du chapitre, lui aussi propriétaire. Lorsqu'il rentre enfin après une longue absence, il n'a d'ailleurs aucune excuse, tout à sa gestion des biens temporels. Du spirituel, qu'il vient de négliger pendant une semaine au moins, il ne sera jamais question : «On m'a dit que vous m'attendiez depuis huit jours, je n'en savais rien, et puis quand on a des affaires, on ne sait pas le temps qu'elles nous tiendront ». Son premier mouvement est de goûter au confort du foyer, au moelleux de sa robe de chambre, à la douceur de son bonnet de nuit; il rêve à haute voix du repas qui se mitonne, au bon cru de 1743 qu'il va savourer.

Ces considérations tiennent lieu de réponses aux questions sur le sacre que place, autant qu'il le peut, l'auteur, de plus en plus impatient. Or, le chanoine considère comme preuve unique de bonne mémoire le récit des menus anciennement dégustés : celui qui l'avait réuni avec ses confrères autour du doyen de l'époque, « un bon vivant qui faisait la meilleure chère du monde ». «Je m'en souviens comme si j'y étais, il nous donna un dîner excellent » est la phrase clé du récit. Cette formule, centrale dans les répliques, va suggérer la procession des mets qui la suit et des convives qui s'en régalent. Potages onctueux, côtelettes de veau que l'on mange par sept ou par onze, mouton de Beauvais, perdrix, jambons au dessert, vins blancs rares, avaient entretenu durant six heures les ripailles des chanoines, certains secs mais gros buveurs, d'aucuns d'une obésité remarquable (Ventrin, «gros comme un orme »), d'autres enfin cultivant «une bonne trogne» et riant la bouche pleine, au détriment des convives les plus proches. Et au déjeuner succédait le souper, pour mieux patienter jusqu'aux matines, jusqu'à l'indigestion. Là s'interrompt la litanie, qui lasse ses auditeurs ; là intervient la gouvernante, pour un ultime effet comique : «Allons, venez, M. le Chanoine; mais une autre fois ne parlez pas tant sans boire. » Alors tombe la morale, l'ultime parole de l'abbé de la Craie, scellant la pièce et ramenant aux vœux de religion bafoués : «Promettre est un et tenir est un autre. »

(7) CARMONTELLE, Le chanoine de Reims, Collection des théâtres français, Senlis, 1829, t. 43 (Proverbes-I). 
Le rire de l'élite restreinte des spectateurs grince d'autant plus que les faits moqués recouvrent des travers plus réels, incidemment et non généralement constatés, qui attisent la légende noire des collégiales. Brissot, dans ses Mémoires, vilipende les chanoines intrigants de la cathédrale de Chartres, s'introduisant dans les foyers pour y conquérir l'esprit des femmes, attirer les âmes simples vers la prêtrise, faire déshériter les autres (8). Et Robert Mandrou a bien montré les rapports gourmands du chapitre de Dole aux arts de la bouche. En 1618, organisant un repas exceptionnel pour seize personnes, les chanoines se faisaient remarquer par l'abondance des produits courants proposés en buffet, sans cuisine raffinée : chevreuil, mouton, trois perdrix, deux dindes, huit cailles, deux levreaux, sept poulets, quatorze pigeons, du lard à larder, des confitures, des câpres, des olives, trois pâtés de pigeon et de venaison, pâtisserie, biscuits, artichauts, cerises, poires, prunes, noisettes... Les mêmes, en 1756, pour recevoir l'archevêque de Besançon, font preuve de goûts culinaires dignes de gourmets, proposant cette fois des plats savamment élaborés suivant les modes alimentaires les plus récentes : bisque d'écrevisse, potage à la reine, grenouilles à la poulette, truites grillées, anguilles en serpentin, filets de brochet, carpes du Doubs avec coulis d'écrevisse, tourte de laitances de carpes, etc. (9). Le théâtre de Carmontelle, élaboré dans le libre entourage du duc d'Orléans, de quelques libertins, de grands qui ne fréquentent guère les chapitres crottés, offre donc bel et bien une once de vérité quoiqu'il semble faire loi universelle des défauts d'un petit nombre. Dans sa forme métaphorique, l'appétit emphatiquement décrit renvoie aussi et peut-être surtout à l'avidité des décimateurs.

Si la scène s'en saisit, la caricature, notamment révolutionnaire, néglige la représentation des chanoines en tant que tels, s'acharnant prioritairement sur les évêques, leurs vicaires, les abbés - dotés ou non de canonicats -, les moines et les religieuses. Faut-il rapprocher cette absence de celles qui ont été repérées en Guyenne par Philippe Loupès, et qui, si l'on pouvait les généraliser, marqueraient les limites à la réception populaire des diatribes contre Yordo canonicus : en cette province, pas de déguisement carnavalesque ridiculisant la condition canoniale, pas de violence contre les collégiales lors des émotions et des émeutes, sauf une exception dans le Montalbanais (10) ? Nous sommes loin des critiques du parasitisme des chapitres cathédraux élevées en Beauce ou dans le Beauvaisis. De même, lorsque le dessin polémique récupère brièvement les chanoines réguliers,

(8) Cité par Michel VOVELLE, art. cit. note 2, p. 269.

(9) Robert MANDROU, Introduction à la France moderne. Essai de psychologie historique (1500-1640), Paris, Albin Michel («L'évolution de l'humanité »), 1961, pp. 30 et 32.

(10) Philippe LOUPES, op. cit., note 4, p. 396. Les habitants de Saint-Sardos, dans le Montalbanais, sujets du chapitre de Sarlat, refusent en 1759 de lui payer le droit banal de forge, organisent des concerts de mousquet nocturnes, détruisent les charrettes du chapitre et dévastent ses greniers, forcent le syndic à danser, etc. 


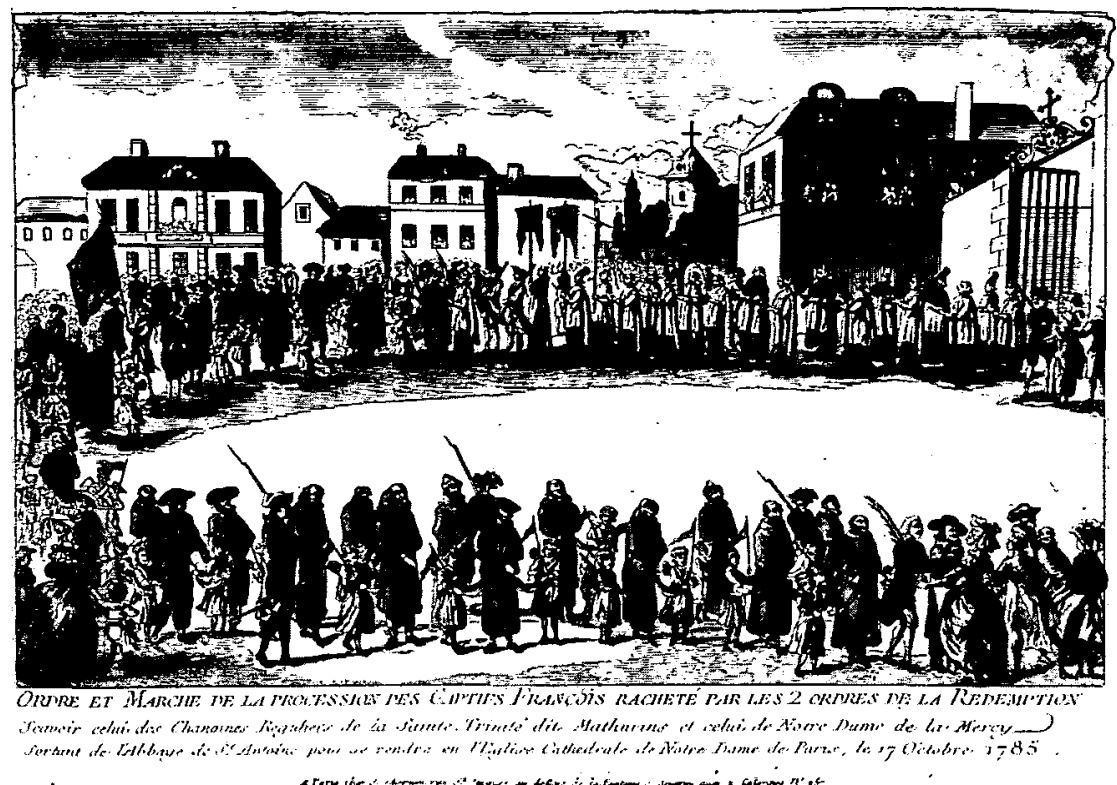

dans une œuvre coloriée vendue en octobre 1785 à Paris par l'une des boutiques d'estampes de la rue Saint-Jacques, chez Chéreau (Ordre et marche de la procession des captifs françois racheté [sic] par les 2 ordres de la Rédemption), c'est pour chanter leurs louanges. La gravure rend compte de la procession parisienne du 17 octobre 1785 qui a suivi le rachat à Alger de trois cent treize esclaves français par deux ordres de chanoines réguliers, ceux de la Sainte-Trinité (les Mathurins) et ceux de Notre-Dame-de-laMerci (les Mercédaires). Les premiers ont ceint les affranchis d'un ruban rouge, les seconds d'un ruban bleu et les ont accompagnés de ville en ville (Aix, Arles, Tarascon, Avignon, Lyon, Troyes, Fontainebleau) avant de gagner la capitale. À chaque étape, aumônes et vêtements ont été distribués aux natifs retrouvés et les bienfaits charitables des réguliers exaltés. L'image proposée est celle de l'heureux dénouement : les enfants libérés, de blanc vêtus, portent couronnes et ailes d'anges; tenus de part et d'autre de leurs bienfaiteurs qui les guident par des écharpes bicolores, ils semblent indéfectiblement liés à des religieux enfin dans le monde, que précédent dans le défilé chanoines séculiers, corporations et soldats (11).

L'imagerie est tout aussi exemplaire si l'on considère le Don patriotique: les besoins de l'État sous les règnes précédens. Dédié et présenté à Mesdames les Chanoinesses du très illustre et noble chapitre de Sainte 


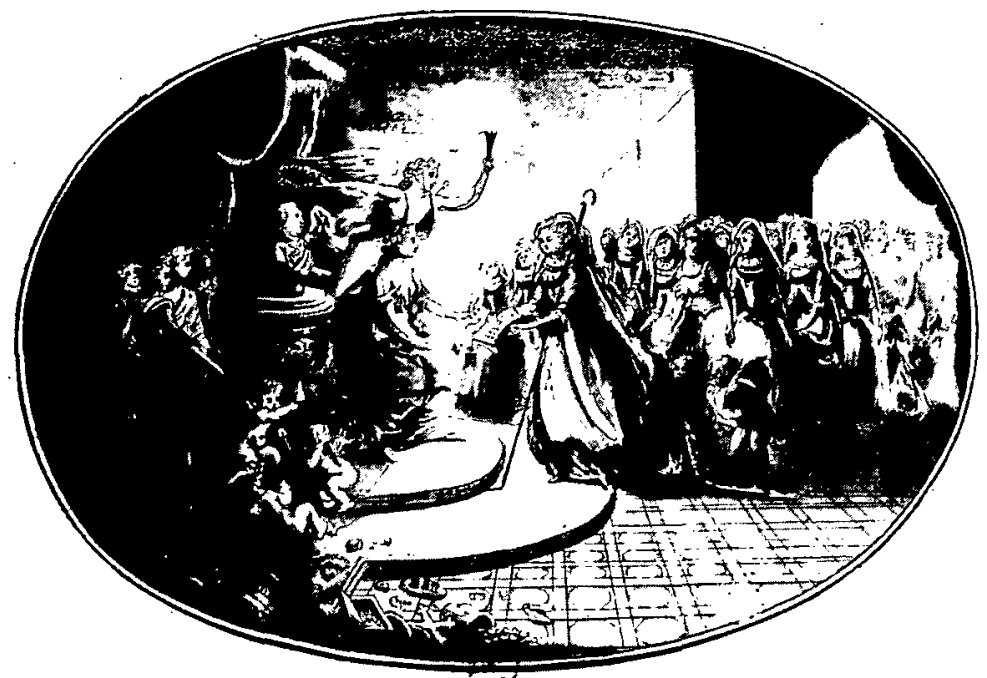

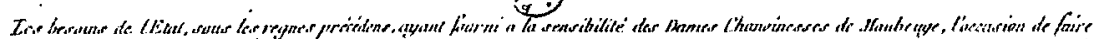

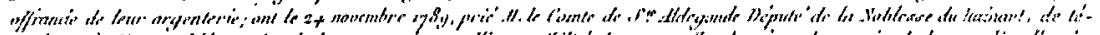

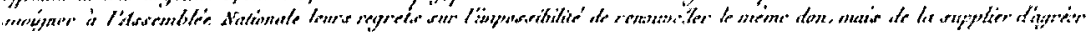

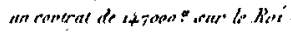

Aldegonde de Maubeuge, œuvre de Cornu vendue en 1790 à Paris (12). Les religieuses, voiles et tabliers blancs, sous la houlette de leur supérieure, se bousculent, respectueusement inclinées, pour faire un don à l'État que représente un buste de Louis XVI protégé par Minerve, des Amours, les génies de la France. Paix, espérance et patriotisme sont mêlés dans cette scène de soumission du clergé féminin à l'État. L'esprit est bien différent dans une gravure contemporaine, $M$. le chanoine rasé de près par les anti-aristocrates (13), qui relève d'une veine patriote et anticléricale, indicatrice des conflits d'ordre que les oppositions politiques et la vente des biens du clergé exacerbent. Au demeurant, la représentation est peu signifiante : seul le large couvre-chef noir, cachant l'air revêche d'un homme le visage déformé par une moue, la nuque dissimulée par un linge ou une perruque défraîchie, portant habit rouge et collet vert, renvoie à un hypothétique vêtement sacerdotal.

Négligés par les dessinateurs, les chapitres abondent marginalement les moqueries des romans pornographiques. Ceux-là mettent en scène, durant tout le XVIII ${ }^{\mathrm{e}}$ siècle, abbés, frères et moniales, rejetant vigoureusement leurs vœux de célibat et de chasteté, manière de rejoindre la société, fût-elle libertine, et de marquer l'inanité de leur état - ce dernier ne contrarie-t-il pas les

(12) BNF, Qb 11789 (24 nov), De Vinck 2860, 10 x 14,5 cm, couleur. À Paris, chez Guyot.

(13) Ibid. (2 nov), 13 x 8 cm, couleur. S.n., Paris. 
libertés élémentaires de l'individu, ses devoirs sociaux parmi lesquels la paternité et la maternité? Sans doute Les Quarante Manières de foutre dédiées au clergé de France, publiées en 1790 à Paris par les presses du Temple de la Volupté, n'excluent-elles ni les chanoines ni les chanoinesses. Plus sûrement, la Dissertation foutromanique sur les plaisirs des chanoines de la collégiale de B..., publiée la même année en appendice - si le terme convient - des Travaux d'Hercules [sic] ou la Rocambole de la Fouterie, les dévoile sans artifice (14). Sous la plume de celui qui se réclame émule de Piron, Grécourt et Gervais, défile une cohorte peu reluisante de corps épuisés, ridiculement déguisés, de vieillards saturés de plaisirs illicites :

«Vous les voyez paraitre, le front ceint d'une vieille peau de zibeline, de chat ou de mouton; les uns avec des visages rubiconds et enluminés d'un rouge nacarat, surchargés de dartres, de boutons et d'échauffures ; les autres, sous les traits livides d'une indolente momie, les yeux mornes et caverneux, les paupières allongées, les joues creuses, la langue surchargée de vapeurs méphitiques, les dents décharnées, le virus prêt à expirer sur les lèvres, la démarche incertaine et chancelante, le buste courbé, les épaules hautes et la tête baissée; enfin, avec tous les symptômes de la débauche et de l'incontinence, de la lubricité et des maladies qui en résultent.

C'est sous ces masques hideux que, chaque jour, appelés par leur état, ils vont dans le sanctuaire de la divinité porter indolemment les restes dégoûtants d'un corps cacochyme, et plein de défectuosités [...], traîner sous le cilice de la religion les vestiges languissants de leur machine épuisée. »

L'auteur, auquel les diverses fortunes des desservants des chapitres n'ont pas échappé, distingue entre les chanoines : les moins aisés se contentent, pour leur usage quotidien, de celles qu'ils prétendent leur cuisinière ou leur ouvrière en linge et qui acquièrent le temps aidant une autorité naturelle sur leurs employeurs; les plus richement prébendés usent pour leurs aventures galantes de jardins et boudoirs élégants, discrètement agencés aux lisières de la ville (on pense inévitablement à la réputation du Parc-auxCerfs). Tous augmentent leur péché de luxure de celui de gourmandise (décidément obsédant), ainsi que les associe volontiers le plaisir libertin : des valets soumis les régalent de repas splendides «où l'abondance des viandes les plus succulentes égale celle des vins les plus exquis » et encouragent leur voracité, payée d'une digestion laborieuse. Ces poncifs de la critique anticléricale, qui servent aussi bien la revendication d'un retour à une Église originelle que l'athéisme, transcrivent métaphoriquement le dédain pour un monde d'oisifs, dont les sources de revenus accablent le petit peuple : son appétit est avant tout stimulé par les impositions; sa décrépitude et son animalité prouvent son incapacité à s'agréger au monde nouveau

(14) Patrick WALD-LASOWSKI, La science pratique de l'amour. Manuels révolutionnaires érotiques, Arles, éditions Philippe Picquier, 1998. 
qui s'ouvre et le rangent aux côtés de nombre d'aristocrates que la critique patriotique affuble des mêmes travers. Les jeux d'esprit rejoignent ainsi les faits vécus ou perçus que transcrivent plusieurs cahiers de doléances.

\section{Les doléances de 1789 ou les chapitres pointés}

Sans que l'on puisse, en l'espace d'un article, en étudier toutes les variations régionales, le thème des chanoines trop richement dotés, spoliateurs, n'apparaît pas avec la même fréquence que celui des frais somptuaires indécents du haut clergé, a fortiori que celui des impôts ecclésiastiques, mais il leur est le plus souvent lié, avec la revendication récurrente de la réutilisation des bénéfices au service des pauvres, de l'éducation, des curés et vicaires. Cette moindre présence tient, entre autres, au fait que chaque église ne disposant pas d'une collégiale, nombre de paroisses ne conçoivent pas d'idées particulières sur le pouvoir des chanoines. Encore l'explication n'est-elle pas suffisante car les rares cahiers de doléances de Guyenne (quatre sur plus de cent) réclamant la disparition des chapitres sont hors de la zone d'influence des compagnies ou tout au moins à leurs marges : issus de la sénéchaussée de Libourne, ils paraissent en vouloir surtout à la collégiale voisine de SaintÉmilion (15). Lorsque les paroissiens à l'inverse acceptent les corps capitulaires, leurs vœux sont-ils parfois orientés par des ecclésiastiques tout puissants ? Eu égard à leur puissance sociale, les doyens en tout cas, quand un bas clergé patriote ne les a pas rejetés (16), attirent quelquefois les regards et les voix lorsqu'il s'est agi de présider des assemblées délibératives. Ainsi, à Saintes, le 31 décembre 1788, le doyen du chapitre cathédral a présidé l'assemblée des trois ordres de la ville réclamant la formation des états provinciaux de Saintonge; il a ensuite vu ces fonctions réitérées lorsque s'est tenue le 5 février 1789 la même réunion, dont il avait coordonné la préparation, à l'échelon de la province ; il est délégué par son ordre en avril pour participer à la rédaction du cahier de doléances de la sénéchaussée et à l'élection des députés aux États généraux; en août 1790, il bénira les drapeaux de la garde nationale (17). De ces responsabilités éminentes au contrôle de l'écriture des cahiers de doléances, il peut n'y avoir qu'un pas. Il

(15) Philippe LOUPES, op. cit. note 4, p. 415.

(16) Abbé LEGRIS, Anecdotes etévénements de la ville et du chapitre de Saintes (du 4 janvier 1781 au 20 mars 1791), Saintes, 1867, p. 17 : « Le onze mars 1789 M. Deluchet chanoine, archidiacre de Saintonge, vicaire général abbé commendataire de l'abbaye royale de Madion en ce diocèse a été nommé par le chapitre pour aller le représenter à l'assemblée générale de la sénéchaussée de St-Jean-d'Angély indiquée au 16 mars dans ladite ville en conséquence de l'assignation faite audit chapitre pour les biens qu'il possède en cette partie. Il a été recommandé à mon dit sieur Deluchet par le chapitre que si dans l'ordre du clergé on refusait obstinément de le reconnaître pour le président du clergé, de faire ses protestations et de se retirer de laditte assemblée ce qui lui ayant été refusé s'est conformé à son mandat et s'est retiré. »

(17) H., pp. 13 et sqq. 
est franchi à Aubiat, dans le Puy-de-Dôme, où l'on plaide pour que ne soit votée «aucune extinction ni réunion de bénéfices sans le consentement des titulaires, collateurs et communautés » et où l'on entend profiter de la Révolution pour éviter les restructurations prévues, en la circonstance la réunion du chapitre d'Artonne à celui du Marthuret, à Riom (18) ?

Ce contrôle de la carte ecclésiastique, qui révèle aussi des concurrences urbaines et des intérêts économiques, est revendiqué pareillement par la ville de Beaujeu en Beaujolais. Elle entend conserver un chapitre riche de dotations et de fondations, sur lequel les chanoinesses de Salles ont des vues, encouragées par l'évêque : "Le motif employé par le Chapitre de Salles pour demander la suppression de celui de Beaujeu est son inutilité sur la montagne, mais la ville qui n'a, pour une assez grande population, qu'un curé et un vicaire, ayant senti la nécessité d'avoir son Chapitre dans la ville, l'a invité de s'y rendre et le Chapitre a généreusement répondu qu'à ses frais il offrait de descendre et de se réunir à l'église paroissiale » (19). Les neuf chanoines de N. D. du Château revendiquent de surcroît de payer désormais un impôt proportionnel à leurs bénéfices, réparti par les administrations provinciales et non au sein du premier ordre, en foi de quoi ils dénoncent le don gratuit; ils plaident pour l'abandon des droits féodaux et des douanes intérieures, pour un renouveau de l'administration («jusqu'à présent un régime incohérent et désastreux ») et des réunions régulières d'états provinciaux élus par des propriétaires de tous les ordres, pour l'abolition des lettres de cachet et un code de procédure civile et criminelle. Mais, forts de leur histoire et de leur puissance temporelle, ils profitent aussi des réunions préparatoires aux États généraux pour rendre public un conflit ecclésiastique entre séculiers et régulières, qui va mobiliser au-delà de leur communauté les citoyens de Beaujeu. Associant au cahier de la ville leurs propres récriminations et revendiquant leur rôle social, ils jouent admirablement des enjeux locaux et, si l'on peut dire, de l'esprit de clocher :

«Que le chapitre de Beaujeu fondé en 1010 par les sires du Beaujolais, qui a subsisté avec honneur pendant près de huit siècles, qui a concouru à la fondation même et à l'accroissement de la ville de Beaujeu dont il est la première ressource, qui dans tous les temps a soutenu l'établissement de l'Hôtel-Dieu, d'un bureau de charité, d'un collège, qui offre à la province l'expectative de douze prébendes canoniales, de plusieurs chapelles et de cinq cures dont la nomination lui appartient; que ce Chapitre attaqué si injustement rentre enfin dans les droits sacrés et inviolables de ses propriétés que cherche à envahir le chapitre noble des chanoinesses de Salles, lesquelles n'offrent à la ville et à la province aucun dédommagement du grand nombre de bénéfices dont elles poursuivent l'extinction.

(18) Francisque MĖGE, Les cahiers des paroisses d'Auvergne en 1789, Clermont-Ferrand, 1899, p. 400.

(19) Cahier de doléances de la ville de Beaujeu, 8 mars 1789, dans Claude FAURE, Cahiers de doléances du Beaujolais pour les États généraux de 1789, Lyon, Imprimerie nouvelle lyonnaise, 1939, p. 19. 
Le Beaujolais ne compte, en effet, que peu de gentilshommes qui puissent y faire admettre leurs enfants, par la rigueur des preuves que l'on y exige. Les places ne sont occupées que par des étrangères. L'intérêt sensible et pressant de la province est de préférer à ce chapitre fermé pour elle, un corps ecclésiastique respectable par son ancienneté même, l'un des plus beaux monuments de la piété et de la bienfaisance des souverains du Beaujolais, qui a toujours adopté pour ses membres les habitants et les originaires de cette province, et nécessaire à une ville qui ne pourrait plus supporter la masse de ses impositions si elle était privée de ses secours. » (20)

L'ouverture sociale mise en exergue par les pétitionnaires correspond à une réelle attente, comme autant de débouchés promis aux fils de la petite et de la moyenne bourgeoisie. À peu de distance de Beaujeu, la paroisse de Belleville réclame par exemple la sécularisation de son abbaye, aux mains, pour les deux tiers de ses revenus, des chanoines réguliers de la Congrégation de France et, pour le dernier tiers, d'un abbé commendataire frappant par son absentéisme : si les canonicats et la maîtrise se libéraient, «les enfants de la ville trouveraient dans ce chapitre une ressource pour soutenir leur famille»(21). Le refus de la réaction nobiliaire et des chapitres dévolus au deuxième ordre conduit à de semblables demandes la communauté lorraine de Bellange : "Que l'entrée des chapitres, l'admission aux dignités ecclésiastiques et aux emplois militaires ne soient point réservés aux nobles seuls » (22). Le Tiers État de la sénéchaussée de Saint-Maixent propose que les bénéfices d'une même personne soient limités à partir d'un certain revenu, le surplus redistribué à de nouveaux bénéficiers (23). La noblesse du bailliage de Sens suggère la disparition des monastères féminins non voués à l'éducation au profit de la fondation de chapitres roturiers de filles («lesquelles ne feront aucun vœu et pourront se marier en quittant leur prébende ») (24). Mais ce sont là les dernières heures de gloire des collégiales.

Ces revendications en effet demeurent minoritaires par rapport au ton dominant qui, avec d'infinies variations, est à la réforme des institutions, voire à leur disparition. Les demandes émanent parfois du premier ordre

(20) M., pp. 23-24.

(21) Id, p. 42. Cahier de doléances du 8 mars 1789.

(22) Charles ÉTIENNE, Cahiers de doléances des bailliages des généralités de Metz et de Nancy pour les États généraux de 1789, $1^{\text {re }}$ série (département de Meurthe-et-Moselle), tome 1 (bailliage de Vic), Nancy, 1907, p. 86. Assemblée du 15 mars 1789.

(23) Léonce CATHELINEAU, Cahiers de doléances des sénéchaussées de Niort et de Saint-Maixent et des communautés et corporations de Niort et de Saint-Maixent pour les États généraux de 1789, Niort, 1912, pp. 410-411 : «Il serait à désirer qu'il intervînt un règlement qui décidât qu'un archevêque, un évêque, un abbé, un prieur, un dignitaire de cathédrale ou d'autres églises, un chanoine, un curé ne pourraient jamais, quand ils jouiraient d'un revenu de 2000 à 2400 livres, provenant de biens d'église, avoir un autre bénéfice ; une pareille loi procurerait un avantage réel à plusieurs individus ».

(24) Charles PORÉE, Cahiers de doléances du bailliage de Sens pour les États généraux de 1789, Auxerre, 1908, p. 816. Cahier du 16 mars 1789. 
lui-même, comme le révèlent les doléances de Jean-Louis Perrot, curé de Conie (Eure-et-Loir). Il voit un abus criant dans les revenus dévolus aux chanoines, moines, abbés, chapelains, comparés à l'indigence des curés et vicaires, chargés, outre la pastorale et la confession, d'accorder aides et hospitalité aux plus pauvres, de parcourir régulièrement leur paroisse pour y apporter conseils et réconfort, d'entretenir le presbytère, sans compter les livres à acheter, si nécessaires à l'étude qui évite excès et désordres. Il plaide pour la suppression « des dignités superflues et des emplois inutiles », l'abolition «sans aucun ménagement» de la plupart des bénéfices (25). À Saint-Didier en Beaujolais, où l'on assure que les bras enlevés au Tiers État pour peupler les collégiales «font tort à la population», on souhaite la suppression des chapitres autres que cathédraux et la vente de leurs biens, qui pour l'heure servent «à entretenir le luxe et la fainéantise ou quelque chose de pire », au profit des établissements d'éducation (26). Les paroissiens de Clermont-sur-Oise reporteraient bien volontiers eux aussi deux prébendes du chapitre, dévolues à des abbés souvent absents, sur la manse du collège "pour y avoir deux précepteurs au lieu d'un et un maître d'écriture, lecture et calcul » (27). À moins d'imaginer, comme à Couffi, dans le Loir-et-Cher, que deux chanoines par chapitre soient prêts à aider curés et vicaires absents pour l'office et surtout pour l'enseignement (28). À SaintJust d'Avray, on utiliserait plutôt l'argent récupéré pour «doter suffisamment les curés, ainsi qu'à fonder des œuvres de charité dans les villes et dans les campagnes » (29). Le retour aux fonctions orantes, l'aide aux curés et vicaires des paroisses crottées, justifient les récriminations de paroissiens de Roquemaure : "Que les prieurs et les églises collégiales qui, primitivement et suivant leur fondation, étaient obligés de desservir les paroisses aient la faculté, la vacance desdites cures arrivant, de rentrer dans leurs droits, mais que les chanoines et bénéficiers soient tenus de faire eux-mêmes le service, sans pouvoir se faire représenter par des locataires ou prêtres amovibles » (30). En bref, le principe d'utilité sociale fédère toutes les remises en cause des bénéficiers, de quelque nature qu'ils soient, associés dans l'opprobre.

(25) Denis JEANSON, Cahiers de doléances de la région Centre. Eure-et-Loir, 2 volumes, Tours, 1990, tome 1, p. 192.

(26) Claude FAURE, Cahiers de doléances du Beaujolais pour les États généraux de 1789, op. cit., note 19, p. 726. Cahier de doléances du 15 mars 1789.

(27) Hélène SIMON, Les cahiers de doléances des pays de l'Oise en 1789. Bailliage de Clermont-enBeauvaisis, Beauvais, Archives départementales de l'Oise, 1996, p. 103. Cahier de doléances du 6 mars 1789.

(28) Denis JEANSON, Cahiers de doléances de la région Centre. Loir et Cher, 2 volumes, Tours, 1989, tome 1, p. 345. Assemblée du $1^{\mathrm{er}}$ mars 1789.

(29) Francisque MÈGE, op. cit. note 18, p. 128. Cahier de doléances s.d.

(30) Emile BUGNY-BONDURAND, Cahiers de doléances de la sénéchaussée de Nîmes, Nîmes, 2 volumes, 1909, tome 2, p. 99. Assemblée du 13 mars 1789. 
« Nous déclarons, proclament les habitants de Mennetou, ne pouvoir voir d'un œil tranquille les exemptions pécuniaires accordées à l'état ecclésiastique, et nous avons à reprocher à notre destinée de nous avoir pas appelé à cet ordre, en y voyant du nôtre des eclésiastique par leur bénéfice dans la plus grande des opulances sans charge d'impôts et nous pauvre en étant accablé.

En effet, combien de chapitre de cathédralle qui donne à chaque chanoinne un revenu plus que suffisants dont la grande partie d'eux y joignent encore des abbaye, archidiaconné, prieuré et autre bénéfice qui leur fait un total de revenu absolument superflu.

Combien d'autre chapitre inutille, d'abbaye, prieuré, commandataire, chevalliers de Malte, communautés des deux sexes inutille pour le soutien de la religion et à charge à l'État [...] tandis que dans les mesme parroisse on voy des pères de famille gémir sous le poid de la misère et de l'infortune, véritables chrétiens, ne pouvoir donner à leurs enfans, les uns le nécessaire à leur subsistance et les autres l'éducation dont quelq'uns seroient suceptible de faire des sujets à l'État, payer la moitié au moins en impositions du revenu de leur modique propriété et du fruit de leur pénible travaux.

Nous ne pouvons donc que gémir et nous plaindre de notre sort en voyant le Clergé posséder la plus grande partie des biens du Royaume, ne rien payer pour le soutien de l'État en comparaison de nous du Tiers État, que par ce défaut d'égalité nous trouvons accablé. » (31)

Dans la rénovation envisagée de l'Église (et de ses promotions), les chanoines métropolitains demeurent, non sans modification de leur statut et de leur recrutement. "Suppression absolue de tous chapitres nobles et roturiers des deux sexes, à l'exception des cathédrales où l'on nommerait les anciens curés qui, ayant porté le poids du jour et de la chaleur dans leur ministère [...] auraient une retraite dans leurs infirmités. De cette réforme le roi acquitterait de leurs revenus les dettes de l'État»(32), suggère-t-on à Vauxrenard. On ne pense guère autrement au sein du clergé de Clermonten-Beauvaisis, dont le cahier de doléances en date du 9 mars 1789 porte expressément l'invitation à «distraire dans chaque diocèse un certain nombre de canonicats de cathédrale et de collégiale à nomination ecclésiastique pour la retraite des curés et autres qui auront blanchy sous le fardeau du ministère »(33) - idée pareillement défendue par le clergé de Vendôme (34); la réduction est plaidée également à Saint-Dionisy, à Saint-Laurent-le-Minier, et le «certain nombre » devient moitié à Cruviers et Lascours (35). Les communautés rurales de Montandon et de Mouillevillers, dans le bailliage bourguignon de Baume-les-Dames, imagi-

(31) Denis JEANSON, op. cit., note 26, tome 1, p. 506. Assemblée du $1^{\mathrm{er}}$ mars 1789.

(32) Francisque MÈGE, op. cit., note 18, p. 150. Cahier de doléances du 11 mars 1789.

(33) Hélène SIMON, op. cit., note 27, p. 393.

(34) Denis JEANSON, op. cit., note 28, tome 2, p. 352. Assemblée du 23 mars 1789.

(35) Émile BLIGNY-BONDURAND, op. cit., note 30, respectivement tome 2, pp. 181 et 290 (assemblées des 14 et 12 mars 1789) et tome 1, p. 276 (assemblée du 14 mars 1789). 
nent la lente disparition des collégiales, supprimées « après la mort des titulaires », et un cursus honorum pour les chanoines des cathédrales qui, afin de ne rien ignorer des réalités de terrain, devront «pour être reçus avoir occupé des cures pendant dix ans » (36) - pendant vingt années et s'ils sont âgés d'au moins cinquante ans, proposait le curé de Conie pour ceux des collégiales (37). Encore faut-il limiter les revenus des promus : 1500 livres par an pour les métropolitains sembleraient raisonnables aux habitants de Teillay-le-Peneux, dans l'Orléanais (38); l'idée d'une rémunération fixe et réduite fait son chemin chez ceux de Saint-Branchs (Indre-et-Loire) (39). Les motifs de formation et de carrière, le souci d'humilité et de présence sur le terrain se combinent avec le désir d'ordre dans les propositions de François Perrot, curé de Saint-Pierre d'Épernon :

«On souffre de voir tant d'abus dans un corps établi pour éclairer l'évêque et servir de règle à tout un diocèse. Pour remédier à un de ceux qui choquent le plus, c'est de convertir tout le revenu en rétributions attachées à chaque office, et diminuer au moins de la moitié de ce qu'ils appellent vacances. Que l'ordinaire ait droit de visiter les chapitres et d'en réformer les abus. Qu'on ne voye plus, au scandale de l'Église, les chapitres toujours luttant contre leurs évêques, se faisant gloire de les braver et, sous prétexte d'avoir seuls le droit de remédier aux abus qui se glissent dans leur corps, les laisser subsister tous. Que tous les canonicats de la cathédrale et autres à l'avenir soient donnés de la manière suivante : 4 réservés aux gradués, 4 autres aux curés, et les 4 derniers réservés à la liberté des évêques, à la charge toutefois qu'ils ne pourront nommer aucun gradué ou non-gradué qui n'ait au moins 38 ans et qui ait servi utilement, soit en qualité de prêtre de paroisse, soit de professeur, au moins 1 ans, à moins qu'ils ne soient licenciés en théologie. Si on conserve aux particuliers le droit de résigner soit pour les cures, soit pour les canonicats, qu'ils soient tenus au moins aux mêmes règles que les ordinaires, c'est-à-dire qu'ils ne puissent disposer de leurs canonicats qu'après 12 ans de service et 6 ans pour les cures. 11 seroit à souhaiter qu'il n'y eût plus d'induits; si on ne juge pas à propos de les abolir, que les règles ci-dessus soient observées. Qu'il n'y ait plus de chanoines aumôniers à la Cour, ou qu'ils optent. » (40)

À Vého, en Lorraine, comme à Marcilly-en-Gault, dans le Loir-et-Cher, certains aspects de la nationalisation des biens d'Église et de la future

(36) Robert JOUVENOT, Le bailliage de Baume-les-Dames en 1789. Les cahiers de doléances, Annales littéraires de l'Université de Besançon, Les Belles-Lettres, Paris, 1985. L'assemblée de la communauté de Montandon s'est réunie le 15 mars 1789, celle de Mouillevillers le 19.

(37) Cf. note 22.

(38) Camille BLOCH, Cahiers de doléances du bailliage d'Orléans pour les États généraux de 1789, tome 1 (bailliage d'Orléans), Orléans, 1906, p. 102. Assemblée du 27 février 1789.

(39) Denis JEANSON, Cahiers de doléances de la région Centre. Indre-et-Loire, 3 volumes, Tours, 1991, tome 3, p. 50. Assemblée du $1^{\text {er }}$ mars 1789.

(40) Denis JEANSON, op. cit. note 25 , tome 1, p. 192. L'induit est un privilège accordé (au pape, au roi, au Parlement, aux cardinaux) pour nommer à certains bénéfices ou pour pouvoir les tenir contre la disposition du droit commun. 
Constitution civile du clergé transparaissent déjà, telle la fonctionnarisation des prêtres, devenus pensionnés de l'État: «Comme on désire dans ce moment de trouver le moyen de pourvoir et subvenir au besoin de l'État sans surcharger le peuple, il seroit un moyen bien facille; ce seroit de s'emparer de tous les biens des moines et chanoines et leur faire à chacun une pension viagère honeste et suffisante pour leurs subsistances, convertir ces biens en espèces et en acquitter les dettes de l'État»(41). Ailleurs, on envisage le regroupement des collégiales si elles ne comptent pas plus de dix individus ou, plus radicalement, la réunion des chanoines dans le seul chapitre cathédral, dont la taille serait proportionnée à celle du diocèse (42).

Les chapitres sont de facto entraînés dans la dénonciation du régime seigneurial dont ils sont bénéficiaires. C'est en souhaitant que la France connaisse enfin l'unité des poids et mesures que la communauté de Mardié s'émeut des trois valeurs différentes auxquelles elle est soumise pour les liqueurs et les grains : la pinte d'Orléans, la pinte de Jargeau et celle du chapitre de Sainte-Croix (43). C'est en plaidant pour l'égalité devant l'impôt que les habitants de Fourques se plaignent des exemptions dont bénéficient les chanoines métropolitains d'Arles, bénéficiaires des trois quarts de la dîme (44). Certains chapitres sont d'ailleurs conscients que le temps est venu de renoncer à un privilège qui, d'une certaine façon, les exclut de la nation. Celui de la cathédrale Saint-Louis de Blois, pourtant attaché à la division et au vote par ordres lors d'États généraux et provinciaux qu'il souhaite réguliers, oublie ainsi ces divisions lorsqu'il s'exprime sur les impositions :

«Le droit de consentir librement l'impôt, de le répartir, de le recouvrer pour le verser directement dans les coffres du Roi, étant devenu commun à tous les citoyens, le Clergé n'aura plus lieu de réclamer des privilèges inhérents à la Nation, dans lesquels il s'était toujours maintenu et dont les autres Ordres s'étaient laissé dépouiller. Nous consentons à payer désormais, sans aucune distinction d'Ordres, toutes les impositions ordinaires et extraordinaires, tant pour la liquidation des dettes de l'État, dans lesquelles seront

(41) Denis JEANSON, op. cit. note 28, tome 1, p. 473. Assemblée de la communauté de Marcilly-enGault, ${ }^{\mathrm{er}}$ mars 1789. Pour Vého, cf. Charles Étienne, Cahiers de doléances des bailliages des généralités de Metz et de Nancy pour les États généraux de 1789, op. cit., note 22, p. 81. Assemblée du 15 mars 1789: «Ladite communauté demanderait que le Clergé paye rétribution à Sa Majesté, soit chanoines séculiers et réguliers, et des deux sexes et autres, etc., qu'ils soient réunis à une pension, qu'ils puissent vivre honnêtement sans tant de superflu ; que, par ce moyen, Sa Majesté trouverait des moyens pour soulager son peuple. »

(42) Denis JEANSON, op. cit., note 39, tome 1, p. 515. Assemblée de la communauté de Veigné, $1^{\mathrm{er}}$ mars 1789 : «Que les chapitres et couvents où il ni a pas 10 chanoines et 10 religieux pour faire l'office soyent réunis, supprimés, que chaques religieux et chanoines seront réglés à 10001 . de fixe, que le surplus de leurs revenus soit porté au Trézor royal et mis en masse. » Tome 3, p. 141. Assemblée de la communauté de Semblançay, 8 mars 1789 : « Il n'y aura dans chaque diocèse qu'un seul chapitre, sous le nom de cathédrale, composé d'un plus ou moins grand nombre de titulaires, suivant l'étendue de chaque diocèse, et tous les autres chapitres ou congrégations de prêtres séculiers quelsconques seront supprimés et anéantis à la mort des titulaires actuels. »

(43) Camille BLOCH, op. at. note 38, p. 123. Assemblée du 28 février 1789.

(44) Émile BUGNY-BONDURAND, op. cit., note 30, tome 1, p. 335. Assemblée du 15 mars 1789. 
comprises celles du Clergé, que les dépenses courantes des départements, qui seront vues, visées et arrêtées par les États généraux. » (45)

Mais c'est la pression fiscale exercée par les riches décimateurs qui revient surtout comme un leitmotiv. Depuis Haudivillers, dans l'Oise, on n'entend que les plaintes douloureuses des paysans qui réclament leurs droits et le premier d'entre eux, celui à la vie : "Que le chapitre soit contraint de fournir les titres qui nous obligent à payer dix-huit du cent et à conduire la dixme avec le champart à la grange dixmeresse au risque de perdre nos moissons dans des temps fâcheux et difficiles »(46). Le même émoi agite les travailleurs de la terre de Ruan, dans le Loiret, assujettis aux chanoines de l'église Saint-Aignan d'Orléans, auxquels ils doivent un sixième des grains récoltés (qu'ils sont astreints de transporter vers un lieu de stockage distant de huit lieues) et un nouveau douzième (47). Et que dire de ceux de Saint-Hilaire-la-Palud, sous la dépendance des chanoines de Poitiers, qui entretiennent les divisions sociales $\mathrm{du}$ monde rural en protégeant leur fermier et en surchargeant les métayers (48) ? L'on ne saurait dresser meilleur tableau des misères du Tiers État que celui auquel s'adonnent les habitants de Valliguière :

«Ce qui grève encore plus l'état d'indigence où les habitants de cette commune se trouvent, c'est la dîme, qu'ils sont astreints de payer à la rigueur, à un chanoine du chapitre d'Uzès, qui n'a paru dans ce lieu que pour y prendre possession de ce bénéfice ; fixée [la dîme, N.A.] au onzième de tous les fruits quelconques, sans en excepter même la toison des bêtes à laine, ainsi que la perception en nature, sur le même taux, des agneaux, ce qui est une surcharge des plus onéreuses; à quoi il serait important de remédier, et d'adoucir le sort des propriétaires, soit en retranchant ou en diminuant une pareille redevance, en proportion de l'augmentation du prix des denrées, qui diffère sensiblement du taux où il était lors de son établissement. Et quand bien même cette réduction s'opérerait, le décimateur en aurait encore trop, puisque, n'étant d'aucune utilité dans la paroisse, il ne devrait pas en retirer un produit purement gratuit, qui n'est pas fait pour alimenter des titres vagues et inutiles, mais pour le service actuel et l'entretien des autels. » (49)

(45) Denis JEANSON, op. cit., note 28, tome 1, p. 124. Assemblée du 26 février 1789.

(46) Hélène SIMON, op. cit., note 27, p. 191. Cahier de doléances du 8 mars 1789.

(47) Denis JEANSON, Cahiers de doléances de la région Centre. Loiret, 3 volumes, Tours, 1989, tome 3, p. 219. Assemblée du 26 février 1789 : les habitants de Ruan demandent que les chanoines payent un impôt proportionnel à leurs biens, rentes et revenus.

(48) Léonce CATHELINEAU, Cahiers de doléances des sénéchaussées de Niort et de Saint-Maixent et des communautés et corporations de Niort et de Saint-Maixent pour les États généraux de 1789, op. cit. note 23, p. 57. Cahier du $1^{\mathrm{er}}$ mars 1789 : «Le meilleur et le plus considérable revenu de cette dite paroisse est possédé par MM. Les chanoines de Poitiers, qui ont la dîme de terrage sur presque toutes les terres à blé et à vin d'icelle; le fermier desquels ne paye pour toute imposition que cent soixante-dix-sept livres treize sous de principal de la taille, tandis que plusieurs métayers, cultivateurs de cette paroisse, dont les fermes n'excèdent pas trois cents livres, payent depuis soixante livres jusqu'à cent livres de taille et plus. »

(49) $I d$, p. 484. Assemblée du 15 mars 1789. Les plaignants rajoutent que le chanoine perçoit ainsi 3000 livres annuelles et demandent qu'il donne au moins une seconde messe les jours de sermon, d'autant que de nombreux voyageurs, empruntant la route de Toulouse à Paris, s'arrêtent dans la paroisse. 
L'âpreté des décimateurs, leur rapidité à créer des droits nouveaux, sont en effet mises en regard de leur absence de charité et de la nécessaire circulation des richesses par les cahiers de doléances (50). À Cassagnoles, on insiste fermement sur l'apport économique et social dont bénéficieraient les campagnes si les bénéficiers étaient résidents : «alors leur revenu se consommerait dans la paroisse et les pauvres seraient assistés, au lieu que MM. Les chanoines de Nîmes, prieurs de cette communauté, consomment leur revenu dans ladite ville, et que par ce moyen les pauvres de la communauté, qui sont en grand nombre, sont privés de toute assistance, attendu que le curé dudit lieu, avec sa pension congrue » (51), ne peut les aider. Les paysans de la paroisse de La Chapelle Saint-Martin, sous la dépendance des chanoines de Tours, les décrivent avares en aumônes (30 livres en trente ans) et rapides aux détournements : ils ont résidé sur place «en qualité de curés militants, plusieurs sous la règle de saint Benoît, et, en se retirant par ordre du Prince à la collégiale de Tours, ils ont emporté avec eux les dîmes, fonds et titres dont ils ne jouissaient plus que comme curés » (52), ne laissant qu'un revenu de 1500 livres au curé et aux deux vicaires qui leur ont succédé. Les Lorrains de Barthelémont-lesBauzemont ne disent pas autre chose : «Nous avons à nous plaindre de la conduite dure des décimateurs envers les pauvres de notre paroisse : de temps immémorial, Messieurs les chanoines et bénédictins perçoivent la dîme au douze sur notre ban et ils n'ont jamais fait aucune aumône, au contraire ; ils ont comme forcé notre communauté à recevoir et à se charger des grosses et menues réparations d'une église qu'ils ont fait bâtir dans le lieu en 1764 » (53). Le coût de l'entretien des bâtiments cultuels, supporté par les communautés villageoises, est en effet un des griefs récurrents adressés aux chapitres, non sans les renvoyer parfois à leurs fonctions premières. Ainsi à Obreck, où la dîme est également partagée entre le curé du cru, l'évêque de Metz et les chanoines de la cathédrale, susurre-t-on : "S'il était possible de charger à l'avenir les bénéficiers des dîmes de l'entretien des église, calice et presbytère, laissant la tour, les cloches, la sacristie et le cimetière à la charge des paroissiens, ceci paraîtrait peut-être répondre aux intentions des fondateurs des bénéfices » (54).

(50) À Mesland, dans le Loir-et-Cher, on demande la «suppression généralle de toutes les communautés régulières et des chapitres qui possèdent des revenus immenses et dont les richesses n'ont point de circulation dans le Roiaume ». Cf. Denis JEANSON, op. cit., note 28, tome 1, p. 518. Assemblée du 6 mars 1789.

(51) Émile BLIGNY-BONDURAND, op. cit., note 30, volume 1, p. 192. Assemblée du 10 mars 1789.

(52) Denis JEANSON, op. cit., note 28, tome 1, p. 283. Assemblée du 7 mars 1789.

(53) Charles ÉTIENNE, op. cit., note 22, p. 81. Assemblée du 15 mars 1789.

(54) Ibidem, p. 565. Assemblée du 15 mars 1789. 


\section{La page tournée des chapitres}

Représentations et réalités nourrissent aussi à partir du mois d'avril 1790 les débats de l'Assemblée nationale constituante sur la suppression des chapitres: Parmi les 1315 élus, dont les 330 du clergé, les chanoines sont une vingtaine, en tenant compte des cinq réguliers (55). Le règlement royal de janvier 1789 pour la convocation aux États généraux a notoirement réduit leurs possibilités de représentation : il a annulé le droit pour les chapitres cathédraux de déléguer automatiquement un député et a condamné les communautés religieuses, quelle que soit leur nature, à ne participer aux assemblées bailliagères qu'à raison d'un représentant pour dix membres - alors que les curés, eux, peuvent siéger personnellement. Comment se faire élire aux États généraux lorsque, comme à Bordeaux, l'assemblée du premier ordre ne compte que six chanoines pour cent à deux cents ecclésiastiques présents? Sans compter les divisions qui affectent les délégations capitulaires périgourdines, conduisant à la séparation entre chanoines de la cathédrale et chanoines impécunieux, qui rallient les curés (56). Ces difficultés à être représenté nourrissent des mécontentements nombreux, en proportion de l'influence sociale et économique du monde capitulaire, que marquent les correspondances échangées entre chapitres. Elles conduisent à la naissance au printemps 1789 de l'Union des Chapitres de France dont le manifeste est produit par les chanoines de Notre-Dame de Paris, sous la plume de l'un d'entre eux, Ruffo de Bonneval : la Protestation du chapitre de l'Église de Paris, adressée en avril au roi, aux ministres, aux personnes d'influence, à toutes les collégiales de France, etc., est soutenue par près de cinquante chapitres cathédraux, quarante autres se bornant à des lettres de remerciements, une autre quarantaine gardant le silence. Des alliances locales entre chapitres ont vu le jour : les Représentations et protestations des chanoines de la cathédrale d'Auch, associés à leurs confrères de Lectoure, devient le manifeste des compagnies gasconnes; en Languedoc, l'archevêque de Narbonne, les évêques d'Agde, Saint-Pons, Béziers, Lodève, les chapitres cathédraux et collégiaux, les abbés et abbesses, les prieurs et les corps de bénéficiers signent les Protestations du principal clergé de la sénéchaussée de Béziers (57). Le tout alimente une réaction populaire tournée dans la capitale contre Bonneval, souvent insulté, et encouragée par une parodie satirique de sa protestation, riche de remarques l'outrageant ou atteignant son chapitre, voire la religion. C'est aussi l'élu aux États généraux que l'on cherche à atteindre.

(55) Sur la description générale de la représentation nationale, voir Timothy TACKETT, Par la volonté du peuple. Comment les députés de 1789 sont devenus révolutionnaires, Paris, 1997.

(56) Philippe LOUPES, op. cit., note 4, pp. 403-404.

(57) Id. 
La vingtaine de chanoines finalement députés à l'Assemblée révèle un âge moyen (52 ans) supérieur à celui de l'ensemble des représentants (46 ans) et même de leur ordre (50 ans) [voir tableau joint] (58). Si l'on excepte le cas de Moutier, réputé au sein du chapitre cathédral d'Orléans pour son manque de zèle mis à l'intérêt général, leur carrière est déjà bien remplie, brillante parfois, pour la plupart vraisemblablement accomplie tandis que d'autres peuvent légitimement escompter un évêché, une attente contrariée par la Révolution ou bientôt comblée par l'intégration au clergé constitutionnel. Plusieurs en tout cas cumulent charges et bénéfices, des vicariats généraux et des cures. Texier est aumônier de la reine. Prieur de Saint-Étienne de Bargemon, de Saint-Michel de Favas et de Notre-Dame d'Espéluque d'Ampus, en Provence, vicaire général de Riez et comte de l'abbaye royale de Saint-Victor de Marseille, Barthélémy Joseph de Villeneuve de Bargemon est admis depuis quarante ans aux honneurs de la Cour. Louis Charrier de la Roche est pour l'heure grand vicaire de Lyon et vice-gérant de l'officialité, prévôt-curé du chapitre noble d'Ainay et prieur du Bois-de-la-Salle en Beaujolais. Coster, après avoir pendant vingt ans occupé la cure de Remiremont, a été fait chanoine, vicaire général, syndic du diocèse et vice-official par l'évêque de Verdun. La Boissière est vicairegénéral du diocèse de Perpignan. Vicaire à Langres puis chanoine de SaintMaclou-de-Bar, Edme Aubert est curé de Couvignon ; Davin en fait office à Saint-Martin de Marseille, dont dépend sa collégiale, tout comme Lompré à Champlitte (Haute-Saône). Font, du chapitre de Pamiers, cumule la même charge à Bénac et à Serres-sur-Arget (Ariège). Jean-François Girard exerce à Montargis, Le Pelletier de Feumusson, membre de la Congrégation de France, à Domfort-en-Champagne, son confrère Jacques Delion de Surade à Plaisance (Vienne), Goubert à Saint-Sylvain de Bellegarde (Creuse). Pourvu d'un prieuré-cure en Maine-et-Loire, Martinet enseigne dans la capitale la philosophie et la théologie à la maison de Beauvais tandis qu'Yvernault, curé de Saint-Aoustrillet, est titulaire de la chaire de morale à la faculté de théologie de Bourges - il produit en 1789 un mémoire contre les innovations pédagogiques des Doctrinaires. Sans oublier l'ancien Jésuite Moutier...

Mal connus, les revenus de leurs seuls bénéfices ne semblent guère les distinguer des catégories supérieures des élus du bas clergé (dont les ressources annuelles varient de 600 à 8000 livres) et la vie à Versailles doit s'avérer dispendieuse pour plus d'un : 2400 livres par an pour Colaud de la Salcette, 3500 pour Charrier de la Roche, 7000 pour Ruffo de Bonneval, bien loin du monde des évêques (58 000 livres en moyenne), ce que traduit

(58) Les éléments biographiques qui suivent ont été tirés des ouvrages suivants : Docteur HOEFFER, Nouvelle biographie générale, Paris, 1842-1866; Roman d'AMAT et alii, Dictionnaire de biographie française, Paris, 1933-1994 ; Edna Hindie LEMAY, Dictionnaire des Constituants, Paris-Oxford, 1991. 
d'ailleurs vigoureusement Colaud dans sa correspondance privée avec le chanoine Agnès, de Die : «Nous sommes [leurs] victimes. Leur luxe effroyable dans la capitale a monté tous les esprits. Il est vraiment étonnant qu'on n'ait pas ouvert les yeux plutôt. On pourroit citer cinq ou six prélats qui entre eux réunissaient plus de trois millions de livres de rente » (59).

Leurs origines sociales sont variées mais rattachent presque tous les chanoines députés aux bourgeoisies urbaines des métiers de la robe et du commerce, même si le prestige de telle ou telle famille, riche de charges royales ou distinguée dans le commerce du luxe, a pu conduire à son intégration dans le deuxième ordre. Seul Villeneuve de Bargemon est le rejeton d'une ancienne et illustre noblesse provençale, son aïeul détenant une baronnie et un grade de lieutenant dans la marine. Le père de François Antoine La Boissière est commissaire des guerres de la province de Roussillon, Charrier de la Roche est le fils d'un président en la Cour des Monnaies de Lyon, François Nicolas Lagoille de Lochefontaine relève d'une vieille famille marchande de Reims anoblie en 1698. Le Peletier de Feumusson, descendant d'un échevin du Mans, vit au sein d'une fratrie largement pourvue d'offices et de bénéfices (ses frères sont respectivement trésorier de France, conseiller d'élection, prêtre oratorien, chanoine régulier). Pierre Philippe Millot, dont deux frères ont également épousé la carrière religieuse, Marc-Antoine Moutier et Sylvain Yvernault ont respectivement grandi à Besançon, à Orléans et à La Châtre (Indre) dans trois clans de robins. Coster vient des milieux de la banque nancéenne. Bonnefoy est l'héritier d'un marchand thiernois, Girard d'un marchand de fil de Laval, Claude Bénigne Lompré d'un épicier-pâtissier maire de Champlitte, Nicolas Texier d'un maître-cuisinier, Louis François Martinet d'un marchand-tanneur.

Leur niveau de formation est élevé. Charrier de la Roche, Lagoille de Lochefontaine et Villeneuve de Bargemon ont été faits docteurs en théologie en Sorbonne, grade qu'ils partagent avec Sylvain Yvernault et François Goubert, qui l'ont obtenu à Bourges, et avec Sigisbert Étienne Coster, frère d'un jésuite et d'un homme de lettres, gradué à Strasbourg. Également licencié en droit, Coster a construit sa réputation sur ses prédications et sur les oraisons funèbres de Stanislas à Nancy (1766) et de Marie Leczinska à Versailles (1768). Lompré a fait sa théologie à l'université de Dijon. Tandis qu'Henri Davin compte parmi les membres de l'académie de Marseille. Louis de Bonnefoy, pourvu d'un canonicat à dix-sept ans en l'église SaintGenès de Thiers, a suivi des études de droit à Paris et s'est fait connaître par différents écrits de circonstance (dont, en 1784, De l'état religieux et, en 1787, à l'occasion de la première assemblée des notables, Ex abrupto) et par ses démêlées judiciaires avec Beaumarchais dont il a parodié deux œuvres : $L a$ 
folle journée reprend le Mariage de Figaro (1784), Lanlaire reprend Tarare (1787) et lui vaut une lettre de cachet l'exilant à cinquante lieues de Paris; La Couronne de fleurs est jouée aux Italiens en 1789 alors que le futur prêtre jureur rejoint l'Auvergne pour rédiger le cahier de doléances de son ordre, occasion de rompre précocement avec l'évêque Bonal. Rares, les appartenances maçonniques ne seront pas gage d'unité de décision : Colaud de la Salcette, dont la famille est largement initiée au travail de la pierre brute, prêtera le serment et sera membre du club des Feuillants; Le Pelletier de Feumusson votera avec la droite, se rangera du côté des réfractaires et choisira d'émigrer.

Certains ont déjà une expérience politique antérieure à 1789 ou concomitante de leur élection : Martinet a participé en 1787 à l'assemblée provinciale d'Anjou puis a représenté le clergé à l'assemblée de la généralité de Touraine; Coster a été présent en 1788 au sein de l'assemblée provinciale de Lorraine et de Bar; député aux états provinciaux de Bourgogne la même année, Lompré y a défendu les intérêts du bas clergé ; Jean-Bernard Font, qui s'avèrera un adversaire résolu des réformes de l'Église, a emporté la députation aux États généraux en en privant son évêque; Delion de Surade a bataillé contre le sien pour faire valoir les intérêts du bas clergé poitevin. Si Martinet refuse dans un premier temps la fusion des ordres, plusieurs se distinguent par leur ralliement précoce au Tiers État puis à la Constitution civile du clergé un an après : Delion, bientôt vicaire épiscopal et acquéreur du couvent des Capucins de Civray, vendu comme bien national, Millot, qui deviendra premier vicaire de l'évêque constitutionnel du Doubs, et Colaud de la Salcette, futur conventionnel puis député au Conseil des Cinq-Cents, rejoignent la salle du Jeu de Paume et militent pour la suppression des dîmes et des privilèges du clergé ; comme eux, Aubert, Bonnefoy, Goubert, Lompré prêteront le serment - les derniers refusant cependant d'être élus au sein du clergé constitutionnel et Lompré se rétractant finalement avant d'émigrer en Suisse en août 1792. Charrier de Roche, acquis à des réformes modérées, sera évêque constitutionnel de Seine-Inférieure, réfutera les arguments des adversaires du serment, multipliera pastorales et circulaires pour prémunir le clergé de son diocèse contre les brefs pontificaux avant de démissionner de son épiscopat en octobre 1791, invitant alors ses confrères à le suivre.

Cependant, ni les expériences politiques passées et les convictions qui ont pu en naître, ni leur pratique de l'art oratoire ne feront des chanoines constituants des députés en vue : leurs interventions en séance sont rarissimes et aucun ne se distinguera jamais parmi les grands orateurs. Les chanoines siégeant à gauche (6 sur 21), fréquentent pour au moins trois d'entre eux les clubs politiques. Ils interviennent proportionnellement davantage que ceux de l'autre bord, plus nombreux (onze prises de parole contre douze). Ils sont aussi davantage présents dans les comités (neuf parti- 
cipations, parfois successivement de la part du même individu, contre cinq), ce qui est logique, la droite renonçant très vite à collaborer aux lois jugées « impies » de la Révolution. La répartition dans les comités (Finances avant tout, secondairement Salubrité, Règlement, Rédaction, Vérifications) peut paraître typique d'une accoutumance à la gestion du temporel acquise au sein des chapitres, d'une sensibilité aux problèmes d'aménagement urbain qui lui est liée. Bonnefoy, qui réfléchit également au problème de la mendicité, complète au mieux sa vocation; mais que dire d'Yvernault, s'initiant aux tâches de police générale avec ses collègues du comité des Recherches ? Nonobstant ces choix particuliers, au total, au sein de l'Assemblée du moins, les représentants des chapitres s'engagent peu et le font modérément, restant dans l'ombre des évêques qu'une majorité suit dans leurs hésitations devant la création de l'assignat (hésitation minoritaire au sein du clergé), dans leur refus de l'annexion d'Avignon, surtout dans leur dénonciation de la Constitution civile du clergé puis du serment. Lagoille de Lochefontaine, Le Peletier de Feumusson, Martinet rallient alors avec obéissance et détermination des positions manifestées à l'extérieur de l'Assemblée et exprimées en son sein par des prélats comme Boisgelin ou Bonal.

Lors de la préparation de la Constitution civile, la tendance à la suppression des chapitres s'affirme en effet nettement; au nom du nouveau régime et de l'Église primitive retrouvée, leur caractère suranné apparaît flagrant pour les réformateurs. Les irréductibles se trouvent évidemment dans les rangs du clergé, tel le curé Mayet, député de Lyon, qui s'acharne à défendre les chanoines des cathédrales. Conseils de l'évêque, ils doivent à ses yeux demeurer et assurer en matière de liturgie « la majesté du culte, [...] la pompe des cérémonies », que «les fidèles soient rappelés plus efficacement à la piété, et se pénètrent, de plus en plus, du respect qu'ils doivent à nos saints mystères ». Ce nécessaire prosélytisme justifie bien une collégiale par diocèse à défaut d'en conserver une par paroisse, d'autant que les chapitres cathédraux, comme le préconisaient certains cahiers de doléances, pourraient selon Mayet constituer des havres de paix pour les pasteurs âgés. Il évalue la dépense occasionnée à 100000 livres par cathédrale, soit un traitement de 3000 livres pour chacun des trente chanoines qui devraient constituer la communauté préservée, et 10000 autres pour les frais d'entretien de l'église ou le salaire des choristes (60).

Le rapport Martineau (61) ne reprend aucune de ces propositions d'aménagement. Chanoines et prébendés des églises cathédrales ne sont plus à ses yeux le clergé de l'évêque, qu'ils formaient à l'origine, le secondant et le remplaçant dans la célébration des offices et l'administration des

(60) AP, tome XII (2 mars-14 avril 1790), p. 244. Séance du 19 mars 1790.

(61) Cf. note 1. 
sacrements. Ils sont devenus des parasites, un groupe de pression n'hésitant pas à s'élever au nom de ses intérêts contre le pouvoir épiscopal, à exclure le prélat des assemblées capitulaires, sinon à l'accepter comme simple chanoine - d'où le recours par celui-ci aux grands vicaires, aux vicaires généraux. Sont-ce les menaces contenues dans le texte de Martineau qui provoquent dans les huit jours une réaction du grand chapitre noble de Strasbourg, proposant aux représentants un don patriotique égal à la moitié de son revenu annuel, pour peu qu'il soit «conservé dans son état actuel»? Les députés patriotes ne retirent de cette offre qu'un peu plus de préventions : ce don conditionnel préjuge de leurs intentions, qui ne se sont pas encore manifestées, se récrient Lameth et Garat; «c'est un plaideur qui veut payer ses juges », s'offusque Lavie, élu de Belfort, qui refuse de faire un cas éventuellement particulier des territoires alsaciens : "Je vous prouverai, clair comme deux et deux font quatre, que vous êtes Français malgré vous » $(62)$.

Il n'empêche, le trouble existe bel et bien au sein de plusieurs chapitres qui s'interrogent sur la politique religieuse de l'Assemblée constituante. Celui de Paris, qui s'est exprimé sur le décret du 13 avril 1790, refusant au catholicisme le titre de religion d'État, est suivi le 5 mai par celui de Rouen : «Ainsi peut-être verrait-on un jour des religions et des sectes de toutes espèces abuser du silence d'une loi qui ne les réprime pas pour s'introduire au sein de ce royaume très-chrétien, ériger leurs temples à côté de nos églises, pratiquer publiquement des cérémonies sacrilèges, et y appeler même le catholique imprudent avec le sectaire abusé. » Lu à la messe paroissiale de plusieurs églises rouennaises, ce libelle est condamné par jugement du tribunal de police de Rouen le 12 mai 1790, selon un prononcé qui renvoie à l'image noire des chanoines : "C'est contre les décrets qui rappellent tous les ministres de la religion à leur institution primitive et qui rendent à la nation les biens destinés pour le soulagement du pauvre, mais depuis trop longtemps dévorés par le luxe, que le libelle s'élève. Voilà le véritable mobile de toutes les agitations. La religion est le prétexte apparent ; la cupidité est le prétexte réel » (63).

La défense des chapitres est produite par l'archevêque d'Aix-enProvence, Boisgelin, porte-parole des critiques du haut clergé, le 29 mai 1790, puis le lendemain par le curé Thiébault, député de Metz (64). Elle repose sur un rappel des origines historiques, voire bibliques, de ces institutions : Thiébault renvoie aux apôtres tandis que Boisgelin insiste sur les «Capitulaires de Charlemagne ». Ils évoquent la législation conciliaire sur la composition des collégiales, sur leurs règles, sur l'observation des offices 
journaliers (renforcée après le concile de Trente, soulignent-ils). Boisgelin refuse qu'un acte civil vienne défaire les lois de l'Église universelle, tout en reconnaissant la nécessité de réformer les abus : «Les législateurs peuvent les rappeler quand on les oublie, et non les détruire, et c'est le dernier état autorisé par l'Église qui doit servir provisoirement de loi. » Il accepte l'idée que les chapitres puissent devenir des lieux de retraite pour les desservants ordinaires, qu'ils gèrent au quotidien la cathédrale - l'attention de l'évêque devant pouvoir se porter également sur chacune des églises de son diocèse -, que leurs bénéfices soient révisés en fonction de leur utilité mais par la seule Église. Il réaffirme la qualité de leur fonction orante : «L'Église [...] a toujours regardé les établissements consacrés à la prière publique comme précieux à la religion et comme un des moyens efficaces pour attirer sur les empires les faveurs et les bénédictions du ciel ». Thiébault, tout en reprenant les arguments et les offres de Boisgelin, essaye d'effrayer les législateurs en leur promettant des procès multiples de la part des héritiers des fondateurs si les bénéfices sont supprimés et en dénonçant le caractère sacrilège d'une telle mesure, de nature à conduire ses auteurs à l'excommunication. Si la suppression des collégiales et des titres de doyen, chantre, etc., devient irrévocable, il propose qu'au moins les titulaires soient préservés dans leurs places jusqu'à leur décès.

L'avocat parisien Treilhard, secondant Martineau au comité ecclésiastique de l'Assemblée, répond aux deux hommes ce même 30 mai 1790 :

«[...] L'inutilité absolue des chapitres de collégiales n'est pas moins universellement reconnue; depuis longtemps leur suppression était arrêté ; et si elle n'a pas été exécutée, c'est parce que, dans les temps passés, les projets les plus utiles et les plus sages rencontraient toujours de grands obstacles dans leur exécution, pour peu qu'ils fussent en opposition avec l'intérêt particulier de quelque personne de crédit.

[Treilhard rappelle alors les temps anciens où les chanoines formaient le conseil de l'évêque, sous la tutelle du prélat qui les entretenait à ses frais]

Mais cette vie commune a cessé depuis bien des siècles et l'intérêt a divisé les évêques des chapitres et les chanoines entre eux. Ils ont autrefois formé le conseil de l'évêque; ils en sont devenus les rivaux, pour ne pas dire les ennemis : ils concouraient avec le prélat pour établir la paix et l'harmonie dans les familles; ils la troublent souvent aujourd'hui par cette foule de procès et de contestations qu'ils suscitent à tout ce qui les environne : ils supportaient le poids de l'administration et des fonctions publiques; ils s'honorent actuellement de n'être tenus à d'autres devoirs qu'à celui de réciter quelques offices ; et ce relâchement est si public et si notoire qu'on représente communément l'insouciance, la mollesse et l'oisiveté sous l'emblème d'un chanoine. » (65)

(65) Id., p. 745. 
Avec ce «communément», tout est dit et l'oraison funèbre des chapitres prononcée, pour partie en raison d'une image sociale qu'ils n'ont pas peu contribuée à alimenter. Leur suppression est entérinée le 12 juillet 1790 par le vote de la Constitution civile du clergé. Commence alors une autre étape de la vie des bénéficiers. Elle est d'abord marquée par d'évidents soucis financiers, qui révèlent souvent au sein des chapitres des solidarités jusqu'alors ignorées - les chanoines de Saint-Pierre de ClermontFerrand sauront ainsi manifester leur solidarité envers leur sacristain, le Suisse, le porte-masse, le bâtonnier, le souffleur de serpent, toutes ces petites gens qui les ont accompagnés dans le service de la liturgie (66). Elle est ensuite caractérisée par des choix politiques, religieux et plus largement professionnels (prestation ou non du serment, installation au sein du clergé constitutionnel, clandestinité ou émigration, abandon de l'état ecclésiastique) qui mériteraient une étude particulière. De ce point de vue, il n'est pas inintéressant de constater la participation nombreuse d'anciens chanoines de collégiales à l'entourage direct des évêques constitutionnels auvergnats - pensons aux promus du chapitre Saint-Pierre de ClermontFerrand : Jean-Baptiste Monestier, premier vicaire de l'évêque constitutionnel Périer puis conventionnel du Puy-de-Dôme ; Pascal-Antoine Grimaud, fidèle de Fouché et administrateur de premier plan à Ville-Affranchie après avoir été le premier vicaire constitutionnel de l'évêque Laurent, dans l'Allier. Cet état de fait varie pourtant considérablement selon les diocèses ; la Guyenne, par exemple, ne le connaît pas. Leurs titres de vicaires permettent-ils aux chanoines auvergnats une promotion que l'Ancien Régime leur interdisait d'espérer ou bien retrouvent-ils dans leur nouveau collège un peu des rites et modes de vie de l'ancien ? Si la réponse à cette dernière question s'avérait positive, la Révolution aurait alors, en quelques départements, partiellement échoué à éradiquer totalement la structure et l'esprit des chapitres. Mais il est aussi permis de penser que certaines des mutations de Yordo canonicus prônées par les cahiers de 1789, appliquées par l'Église au $\mathrm{xix}^{\mathrm{e}}$ siècle, n'ont pas peu contribué à construire une nouvelle image du chanoine, "vieux curé méritant, auquel son évêque accorde avec le canonicat son bâton de maréchal et une retraite médiocre mais honorable » (67).

Philippe BOURDIN

Centre d'Histoire «Espaces et Cultures » Université Blaise-Pascal (Clermont-Ferrand II)

103, boulevard La Fayette

63000 Clermont-Ferrand

philippe.BOURDIN@lettres.univ-bpclermont.fr

(66) Philippe BOURDIN, op. cit., note 5, p. 224.

(67) Philippe LOUPES, op. cit., note 4, p. 14. 
Les chanoines constituants

\begin{tabular}{|c|c|c|c|c|c|}
\hline Noms & $\begin{array}{l}\text { Lieux } \\
\text { d'origine }\end{array}$ & Chapitre & $\begin{array}{l}\text { Age } \\
\text { en } \\
1789\end{array}$ & $\begin{array}{l}\text { Nombre } \\
\text { d'interventions } \\
\text { à l'Assemblée }\end{array}$ & Opinions \\
\hline Edime AuBERT & $\begin{array}{l}\text { Chaumont } \\
\text {-en-Bassigny }\end{array}$ & $\begin{array}{l}\text { ch. Honoraire } \\
\text { de St-Maclou }\end{array}$ & 51 & 2 & rallié au Tiers État, Feuillant, jureur \\
\hline Louis DE BONNEFOY & Thiers & St-Genès & 41 & $\begin{array}{l}2 \text { (participe à } 4 \\
\text { comités : Finances, } \\
\text { Mendicité, Rédaction, } \\
\text { Salubrité) }\end{array}$ & rallié au Tiers État, Jacobin, jureur \\
\hline $\begin{array}{l}\text { Louis CHARRIER } \\
\text { DE LA ROCHE }\end{array}$ & Lyon & $\begin{array}{l}\text { prévôt chapitre } \\
\text { noble d'Ainay }\end{array}$ & 51 & $\begin{array}{l}4 \text { (participe au comité } \\
\text { des Vérifications) }\end{array}$ & $\begin{array}{l}\text { rallié au Tiers Etat, à gauche, jureur } \\
\text { (futur évêque constitutionnel) }\end{array}$ \\
\hline $\begin{array}{l}\text { Jacques Bernardin } \\
\text { COLAUD DE LA } \\
\text { SALCETTE }\end{array}$ & Romans & cathédrale de Die & 56 & $\begin{array}{l}3 \text { (3 comités : Finances, } \\
\text { Lquidation, Règlement) }\end{array}$ & $\begin{array}{l}\text { Franc-maçon, rallié au Tiers-État, } \\
\text { Feuillant, jureur }\end{array}$ \\
\hline $\begin{array}{l}\text { Sigisbert Étienne } \\
\text { COSTER }\end{array}$ & Verdun & $\begin{array}{l}\text { cathédrale de } \\
\text { Verdun }\end{array}$ & 55 & 1 & $\begin{array}{l}\text { à droite, contre les assignats, le ratta- } \\
\text { chement d'Avignon, la CCC et le } \\
\text { serment, émigrera (1793) }\end{array}$ \\
\hline Henri DavIN & Marseille & St-Martin & 71 & 0 & rejoint le Tiers État, vote à droite \\
\hline Jean-Bernard FONT & Pamiers & N.D.-du-Camp & 42 & 0 & $\begin{array}{l}\text { à droite, contre les assignats, le ratta- } \\
\text { chement d'Avignon, la CCC et le } \\
\text { serment, réfractaire actif }\end{array}$ \\
\hline Jean-François GIRARD & Montargis & doyen & 56 & 1 (comité de Salubrité) & $\begin{array}{l}\text { rejoint le Tiers État, à droite, contre les } \\
\text { assignats, le rattachement d'Avignon, } \\
\text { la CCC et le serment, réfractaire actif }\end{array}$ \\
\hline Françis GoUBERT & Guéret & $\begin{array}{l}\text { prévôt duch. } \\
\text { d'Aubusson }\end{array}$ & 54 & 1 & $\begin{array}{l}\text { rejoint le Tiers État, à droite, contre } \\
\text { les assignats }\end{array}$ \\
\hline $\begin{array}{l}\text { François Antoine } \\
\text { LA BOISSIÉRE }\end{array}$ & Perpignan & cathédrale & 55 & 1 & $\begin{array}{l}\text { à droite, contre les assignats, le } \\
\text { rattachement d'Avignon, la CCC et } \\
\text { le serment, émigrera (1792) }\end{array}$ \\
\hline $\begin{array}{l}\text { François Nicolas } \\
\text { LAGOILLE DE } \\
\text { LOCHEFONTAINE }\end{array}$ & Reims & $\begin{array}{l}\text { sénéchal du ch. } \\
\text { cathédral }\end{array}$ & 50 & 0 & $\begin{array}{l}\text { à droite, contre les assignats, le } \\
\text { rattachement d'Avignon, la CCC } \\
\text { et le serment, émigrera (1792) }\end{array}$ \\
\hline $\begin{array}{l}\text { Charles Emmanuel } \\
\text { LE PELLETIER DE } \\
\text { FEUMUSSON } \\
\end{array}$ & Le Mans & $\begin{array}{l}\text { régulier de la } \\
\text { congrégation de } \\
\text { France }\end{array}$ & 59 & 0 & $\begin{array}{l}\text { Franc-maçon, à droite, contre les } \\
\text { assignats, le rattachement d'Avignon, } \\
\text { la CCC et le serment, émigrera (1792) }\end{array}$ \\
\hline $\begin{array}{l}\text { Claude Bénigne } \\
\text { LOMPRÉ }\end{array}$ & Vesoul & $\begin{array}{l}\text { collégiale de } \\
\text { Champlitte }\end{array}$ & 54 & 0 (comité des Finances) & $\begin{array}{l}\text { rejoint le Tiers Etat, à gauche, vote } \\
\text { contre les assignats, rétractera son } \\
\text { serment, émigrera (1792) }\end{array}$ \\
\hline $\begin{array}{l}\text { Louis François } \\
\text { MARTINET }\end{array}$ & Angers & $\begin{array}{l}\text { congrégation de } \\
\text { France }\end{array}$ & 36 & 0 & $\begin{array}{l}\text { à droite, contre les assignats, le ratta- } \\
\text { chement d'Avignon, la CCC et le } \\
\text { serment, émigrera (1792) }\end{array}$ \\
\hline $\begin{array}{l}\text { Pierre Philippe } \\
\text { MாцOT }\end{array}$ & Besançon & Ste-Madeleine & 50 & 0 & $\begin{array}{l}\text { rejoint le Tiers État puis dérmissionne, } \\
\text { jureur (futur premier vicaire consti- } \\
\text { tutionnel) }\end{array}$ \\
\hline Marc Antoine MouTIER & Orléans & cathédrale & 59 & 0 & siège à droite, réfractaire \\
\hline RUFFO DE BONNEVAL & Paris & église de Paris & 47 & 3 & $\begin{array}{l}\text { a droite, contre les assignats, le } \\
\text { rattachement d'Avignon, la CCC, } \\
\text { émigrera }\end{array}$ \\
\hline $\begin{array}{l}\text { Jacques DELION DE } \\
\text { SURADE }\end{array}$ & Poitiers & $\begin{array}{l}\text { congrégation de } \\
\text { France }\end{array}$ & 51 & 0 (comité des Finances) & $\begin{array}{l}\text { rejoint le Tiers État, contre les } \\
\text { assignats, jureur et acheteur de } \\
\text { biens nationaux, futur vicaire } \\
\text { constitutionnel }\end{array}$ \\
\hline $\begin{array}{l}\text { Nicolas Jean-René } \\
\text { TEXIER }\end{array}$ & Chartres & cathédrale & 40 & & $\begin{array}{l}\text { à droite, contre, les assignats, le } \\
\text { rattachement d'Avignon, la CCC, } \\
\text { jureur }\end{array}$ \\
\hline $\begin{array}{l}\text { Barthélémy Joseph } \\
\text { VILLENEUVE DE } \\
\text { BARGEMON }\end{array}$ & Marseille & $\begin{array}{l}\text { Chantre, chanoine } \\
\text { et comte de l'abbaye } \\
\text { royale de St-Victor }\end{array}$ & 69 & $\begin{array}{l}4 \text { (comité de Vérification, } \\
3 \text { discours imprimés) }\end{array}$ & $\begin{array}{l}\text { rejoint le Tiers État, à droite, vote } \\
\text { contre les assignats et le rattache- } \\
\text { ment d'Avignon, émigrera (?) }\end{array}$ \\
\hline$\overline{\text { Sylvain YVERNAULT }}$ & Bourges & St-Ursin & 49 & $\begin{array}{l}1 \text { (2 comités : Rapports } \\
\text { et Recherches) }\end{array}$ & $\begin{array}{l}\text { rejoint le Tiers État, à droite, refuse } \\
\text { rattachement d'Avignon et CCC }\end{array}$ \\
\hline
\end{tabular}

$\mathbf{C C C}=$ Constitution civile du clergé

Les renseignements ci-dessus sont extraits de l'ouvrage d'Edna Hindie LEMAY, Dictionnaire des Constituants, Paris-Oxford, 1991, 2 volumes. 